\title{
Caracterização dos estabelecimentos agropecuários da região sul do Brasil com base no Censo Agropecuário 2006
}

\author{
Laura Wichrowski Gauterio* \\ Izete Pengo Bagolin**
}

\begin{abstract}
RESUMO - O estudo fornece uma caracterização da agropecuária da região sul do Brasil com base nos dados disponíveis no Censo Agropecuário 2006. São analisados os aspectos econômicos, sociais e ambientais da agropecuária da região sul frente ao contexto nacional e regional. No que concerne aos aspectos econômicos, o artigo expõe as análises da receita, da despesa, da dívida, do investimento e do financiamento. Das condições sociais, são analisadas a condição legal do produtor em relação à terra, a escolaridade do produtor, o fornecimento de orientação técnica e a posse de eletrodomésticos que permitem acesso a informação. Dos aspectos ambientais, são apresentadas informações relativas ao uso de adubos, de agrotóxicos, de agricultura orgânica e às práticas agrícolas.
\end{abstract}

Palavras-chave: Censo Agropecuário. Caracterização socioeconômica e ambiental da agropecuária.

\section{INTRODUÇÃO}

Ao se estudar a atividade agropecuária brasileira, a utilização dos ou consulta aos dados do Censo Agropecuário nacional é necessária. O Censo Agropecuário é o principal e mais completo levantamento sobre a agropecuária nacional. Ademais, os resultados do Censo Agropecuário estão em consonância com as recomendações da Food and Agriculture Organization of the United Nation - FAO (Organização das Nações Unidas para a Agricultura e Alimentação), o que permite a comparabilidade internacional dessas estatísticas. Apesar da disponibilidade desses dados, faltam análises que permitam obter um panorama ou uma caracterização das atividades agrícolas e pecuárias a nível nacional e regional.

Conforme o último Censo Agropecuário Brasileiro (2006), há no Brasil 5,17 milhões de estabelecimentos agropecuários, os quais ocupam uma área equivalente a 329,94 milhões de hectares. Do total de estabelecimentos do país, 88,81\% (4,59 milhões) obtêm produção, sendo o valor dessa 143,82 bilhões de reais. Na região sul estão situados 19,44\% (1,01 milhão) dos estabelecimentos agropecuários brasileiros, os quais ocupam 12,59\% (41,52 mihões) da área agrí-

\footnotetext{
* Graduanda em Economia pela Pontifícia Universidade Católica do Rio Grande do Sul. É bolsista de Iniciação Científica PIBIC/CNPq. Endereço eletrônico: laura.gauterio@acad.pucrs.br.

** Doutora em Economia pela Universidade Federal do Rio Grande do Sul. É professora do Programa de PósGraduação em Economia da Pontifícia Universidade Católica do Rio Grande do Sul. Endereço eletrônico: izete. bagolin@pucrs.br.
} 
cola nacional. O número de estabelecimentos com produção na região sul representa 20,30\% (933,01 mil) dos estabelecimentos com produção agropecuária do país. O valor da produção da região constitui $28,83 \%$ (41,46 bilhões) do nacional.

Dada a importância da agropecuária da região sul do Brasil para o desenvolvimento econômico da própria região e do país, esse estudo objetiva apresentar uma caracterização econômica, social e ambiental dos estabelecimentos agropecuários da região sul do Brasil, evidenciando a sua inserção e participação no contexto nacional.

\section{ASPECTOS ECONÔMICOS}

O valor anual das receitas dos estabelecimentos agropecuários nacionais é de 121,83 bilhões de reais, representando as provenientes da região sul 28,71\% desse valor. Enquanto 69,96\% dos estabelecimentos nacionais geram receitas, na região sul esse valor é de 80,05\%. Entre os estados da região sul, o Rio Grande do Sul é o que possui maior número de estabelecimentos com receitas (82,55\%), seguido de Santa Catarina (79,79\%) e do Paraná (77,20\%).

TABELA 1 - PARTICIPAÇÃO RELATIVA DO VALOR DAS RECEITAS DOS ESTABELECIMENTOS AGROPECUÁRIOS DOS ESTADOS DA REGIÃO SUL NA MESMA E NO BRASIL (\%)

\begin{tabular}{r|r|r}
\hline \multicolumn{3}{|c}{ BRASIL (\%) REGIÃO SUL (\% ) } \\
\hline PR & 11,46 & 39,91 \\
\hline SC & 5,84 & 20,34 \\
\hline RS & 11,41 & 39,75 \\
\hline REGIÃO SUL & 28,71 & 100,00 \\
\hline
\end{tabular}

FONTE: Elaboração das autoras com base no Censo Agropecuário 2006 (IBGE).

TABELA 2 - PARTICIPAÇÃO RELATIVA DE ESTABELECIMENTOS AGROPECUÁRIOS COM RECEITAS EM RELAÇÃO AO TOTAL DE ESTABELECIMENTOS (\%)

\begin{tabular}{l|r}
\hline BRASIL & 69,96 \\
\hline REGIÃO SUL & 80,05 \\
\hline PR & 77,20 \\
\hline SC & 79,79 \\
\hline RS & 82,55 \\
\hline
\end{tabular}

FONTE: Elaboração das autoras com base no Censo Agropecuário 2006 (IBGE).

Dentre os estabelecimentos da região sul que geram receitas, 52,63\% têm por atividade agrícola a lavoura temporária e 36,75\% a pecuária e criação de animais. Os demais 10,62\% têm por atividade econômica horticultura e floricultura; produção florestal de florestas nativas; produção florestal de florestas plantadas; pesca; aquicultura; ou sementes, mudas e outras formas de propagação vegetal. Quanto ao valor das receitas, 55,15\% provêm da lavoura temporária e $27,77 \%$ da pecuária e criação de animais, estando os demais 17,08\% distribuídos nas catego- 
rias restantes.

O valor anual das despesas dos estabelecimentos agropecuários do Brasil é de 111,29 bilhões de reais. As despesas da região sul representam 23,63\% do valor total das despesas dos estabelecimentos nacionais.

$\mathrm{Na}$ região sul, 48,13\% dos estabelecimentos com despesas têm por atividade a lavoura temporária e 39,32\% a pecuária e criação de animais, estando os demais 12,55\% distribuídos nas categorias restantes. Quanto ao valor das despesas, 55,23\% provêm da lavoura temporária e $29,92 \%$ da pecuária e criação de animais, estando os demais 14,85\% distribuídos nas categorias restantes.

O valor anual das dívidas dos estabelecimentos agropecuários do Brasil é de 26,81 bilhões de reais, representando as da região sul 33,24\% desse valor. Dentre os estados da região sul, o Rio Grande do Sul é o que possui maior número de estabelecimentos com dívidas, considerando valores relativos ao próprio estado, representando eles 40,14\% do total do estado, seguido de Santa Catarina, com 38,57\% e do Paraná, com 29,35\%.

Em relação às dívidas, na região sul 58,95\% dos estabelecimentos com dívidas têm por atividade a lavoura temporária e 33,71\% a pecuária e criação de animais, estando os demais 7,34\% distribuídos nas categorias restantes. Quanto ao valor dessas, 69,64\% provêm da lavoura temporária e $23,86 \%$ da pecuária e criação de animais, estando 6,50\% distribuídos entre as demais categorias.

O valor anual dos investimentos dos estabelecimentos agropecuários do Brasil é de 20,96 bilhões, representando os da região sul $27,71 \%$ desse. Dentre os estados da região sul, Santa Catarina é o que possui maior número de estabelecimentos que investiram, considerando valores relativos ao próprio estado, representando eles 31,42\% do total do estado, seguido do Rio Grande do Sul, com 27,23\% e do Paraná, com 22,85\%.

Dentre os estabelecimentos que investiram no ano, 45,50\% praticam a pecuária e criação de animais e 43,53\% a lavoura temporária, estando os demais 10,97\% distribuídos nas categorias restantes. Na região sul, 46,83\% do valor dos investimentos provêm da lavoura temporária e 34,05\% da pecuária e criação de animais, estando os demais 19,12\% distribuídos nas categorias restantes citadas anteriormente.

O valor anual dos financiamentos dos estabelecimentos agropecuários do Brasil é de 21,52 bilhões de reais, obtendo a região sul uma parcela do valor dos financiamentos equivalente a 29,50\% em relação ao país. Dentre os estados da região sul, o Rio Grande do Sul é o que possui maior número de estabelecimentos que obtiveram financiamento, considerando valores relativos ao próprio estado, conforme pode ser visto nas tabelas a seguir. 
TABELA 3 - PARTICIPAÇÃO RELATIVA DO VALOR DOS FINANCIAMENTOS DOS ESTABELECIMENTOS AGROPECUÁRIOS DOS ESTADOS DA REGIÃO SUL NA MESMA E NO BRASIL (\%)

\begin{tabular}{r|r|r|}
\hline \multicolumn{3}{|c|}{ BRASIL (\%) REGĨ̃O SUL (\%) ) } \\
\hline PR & 11,97 & 40,58 \\
\hline SC & 4,62 & 15,66 \\
\hline RS & 12,91 & 43,76 \\
\hline REGIÃO SUL & 29,50 & 100,00 \\
\hline
\end{tabular}

FONTE: Elaboração das autoras com base no Censo Agropecuário 2006 (IBGE).

TABELA 4 - PARTICIPAÇÃO RELATIVA DE ESTABELECIMENTOS AGROPECUÁRIOS QUE OBTIVERAM FINANCIAMENTO EM RELAÇÃO AO TOTAL DE ESTABELECIMENTOS (\%)

\begin{tabular}{l|r}
\hline BRASIL & 17,76 \\
\hline REGIÃO SUL & 36,50 \\
\hline PR & 29,93 \\
\hline SC & 37,29 \\
\hline RS & 41,68 \\
\hline
\end{tabular}

FONTE: Elaboração das autoras com base no Censo Agropecuário 2006 (IBGE).

$\mathrm{Na}$ região sul, 59,96\% dos estabelecimentos que obtiveram financiamentos no ano praticam a lavoura temporária e 32,86\% a pecuária e criação de animais, estando os demais 7,18\% distribuídos nas categorias restantes citadas anteriormente. Quanto ao valor dos financiamentos, 70,21\% são destinados à lavoura temporária e 23,45\% à pecuária e criação de animais, sendo os demais $6,34 \%$ distribuídos nas categorias restantes.

\section{ASPECTOS SOCIAIS}

O número de estabelecimentos agropecuários do Brasil nos quais o próprio produtor é proprietário das terras é equivalente a $76,25 \%$ do total de estabelecimentos. Os demais $23,75 \%$ têm por principal representante a condição ocupante $(7,97 \%)$, seguido de produtor sem área $(4,93 \%)$, arrendatário $(4,45 \%)$ e assentado sem titulação definitiva $(3,66 \%)$ e, por último a condição de parceiro $(2,74 \%)$. Na região sul, apenas os valores referentes às condições de proprietário $(83,45 \%)$ e arrendatário $(5,91 \%)$ são superiores quando comparados aos nacionais apresentados anteriormente, sendo os demais inferiores. Dentre os estados da região sul, Santa Catarina é o que possui maior número de estabelecimentos no qual o produtor é proprietário das terras, representando eles $88,25 \%$ do total do estado, sendo os valores relativos ao Rio Grande do Sul e ao Paraná, respectivamente, 84\% e 80,29\%.

Constata-se que, do total de estabelecimentos com produtores arrendatários no Brasil, 25,85\% deles encontram-se na região sul, e dos proprietários, $21,28 \%$, sendo essas duas condições legais as mais expressivas na região, em relação ao Brasil. 
O número de estabelecimentos no Brasil com dirigentes que possuem algum nível de instrução formal é de $66,25 \%$ do total. O nível de instrução mais expressivo dentre os dirigentes é o ensino fundamental incompleto, com valor de $42,35 \%$, seguido pelo não sabe ler e escrever, com $24,50 \%$. O percentual de dirigentes que não têm algum nível de instrução, mas sabem ler e escrever, aparece em sequência, com um valor de 9,25\% do total, seguido pelo ensino fundamental completo, com um valor de $8,44 \%$ em relação ao total e do ensino médio completo, com 5,98\%. Os dirigentes que são alfabetizados representam 5,32\% do total. Os demais 4,16\% estão distribuídos nas categorias outra formação superior (2,36\%), ensino médio completo com técnico agrícola (1,35\%), engenheiro agrônomo $(0,29 \%)$, veterinário $(0,11 \%)$, zootecnista $(0,03 \%)$ e engenheiro florestal $(0,02 \%)$.

$\mathrm{Na}$ região sul, 91,53\% dos dirigentes possuem algum nível de instrução formal, obtendo a região sul uma parcela desses equivalente a $26,86 \%$ em relação ao país. Na região sul, do total dos dirigentes dos estabelecimentos, $63,79 \%$ possuem ensino fundamental incompleto; 11,99\% ensino fundamental completo; 7,66\% ensino médio completo; 4,67\% não sabem ler nem escrever; 3,8\% nenhum nível de instrução, mas sabem ler e escrever; $2,84 \%$ são alfabetizados; $2,71 \%$ possuem outra formação superior; $1,86 \%$ ensino médio completo com técnico agrícola; $0,42 \%$ são engenheiros agrônomos; $0,18 \%$ veterinários; 0,04\% zootecnistas e 0,04\% engenheiros florestais. Interessante observar que apenas os valores relativos as categorias não sabe ler nem escrever; nenhum nível de instrução, mas sabem ler e escrever; e alfabetizado são inferiores quando comparados aos nacionais apresentados anteriormente, sendo os demais superiores.

Dentre os estados da região sul, Santa Catarina é o que apresenta maior número de pessoas dirigentes de estabelecimentos que possuem algum tipo de instrução formal em relação ao total de estabelecimentos, conforme se observa na Tabela 6.

TABELA 5 - PARTICIPAÇÃO RELATIVA DE ESTABECIMENTOS AGROPECUÁRIOS COM DIRIGENTES QUE POSSUEM ALGUM NÍVEL DE INSTRUÇÃO FORMAL DOS ESTADOS DA REGIÃO SUL NA MESMA E NO BRASIL (\%)

\begin{tabular}{r|r|r}
\hline \multicolumn{3}{|c}{ BRASIL (\%) REGIÃO SUL (\%) } \\
\hline PR & 9,52 & 35,46 \\
\hline SC & 5,33 & 19,86 \\
\hline RS & 12,00 & 44,69 \\
\hline REGIÃO SUL & 26,86 & 100,00 \\
\hline
\end{tabular}

FONTE: Elaboração das autoras com base no Censo Agropecuário 2006 (IBGE). 
TABELA 6 - PARTICIPAÇÃO RELATIVA DE ESTABELECIMENTOS AGROPECUÁRIOS COM DIRIGENTES QUE POSSUEM ALGUM NÍVEL DE INSTRUÇÃO FORMAL EM RELAÇÃO AO TOTAL DE ESTABELECIMENTOS (\%)

\begin{tabular}{l|r}
\hline BRASIL & 66,25 \\
\hline REGIÃO SUL & 91,53 \\
\hline PR & 88,01 \\
\hline SC & 94,43 \\
\hline RS & 93,22 \\
\hline
\end{tabular}

FONTE: Elaboração das autoras com base no Censo Agropecuário 2006 (IBGE).

Constata-se que, a níveis estaduais, todos os estados da região sul possuem seu valor mais expressivo no número de dirigentes com nível de instrução ensino fundamental incompleto. Do total de pessoas que dirigem estabelecimentos agropecuários no Rio Grande do Sul, $71,39 \%$ dessas possuem ensino fundamental incompleto. Em Santa Catarina, esse valor é de 66,27\% e no Paraná, 53,45\%. Enquanto 24,50\% dos dirigentes de estabelecimentos agropecuários do país não sabem ler nem escrever, em Santa Catarina, no Rio Grande do Sul e no Paraná esses valores são de, respectivamente, $2,7 \%$, 4,23\% e 6,22\%.

O número de estabelecimentos do Brasil que recebe algum tipo de orientação técnica é equivalente a $22,12 \%$ do total. Em números absolutos, 1,14 milhão de estabelecimentos brasileiros recebem orientação técnica, sendo que a parcela referente a região sul é 42,58\% desse valor. Dentre os estados da região sul, Santa Catarina é o que possui maior número de estabelecimentos que recebe algum tipo de orientação técnica, representando 53,71\% do total do estado, seguido do Rio Grande do Sul (49,82\%) e do Paraná (44,08\%). Constata-se que, do total de estabelecimentos agropecuários que recebe orientação técnica na região sul, 15,64\% dessa orientção é fornecida pelo Governo e 15,06\% é fornecida por cooperativas.

O número de estabelecimentos agropecuários do Brasil que possui algum tipo de eletrodoméstico que permite acesso à informação (número de estabelecimentos agropecuários que têm televisão com antena comum; televisão com antena parabólica; videocassete; DVD; rádio; computador; e/ou acesso à internet) é equivalente a 78,10\% do total de estabelecimentos. Dentre os estados da região sul, Santa Catarina é o que possui maior número de estabelecimentos com eletrodomésticos que permitem acesso à informação, sendo 91,36\%. 
TABELA 7 - PARTICIPAÇÃO RELATIVA DE ESTABECIMENTOS AGROPECUÁRIOS COM ELETRODOMÉSTICOS DOS ESTADOS DA REGIÃO SUL NA MESMA E NO BRASIL (\%)

\section{BRASIL (\%) REGIÃO SUL (\%)}

\begin{tabular}{rrr} 
PR & 7,56 & 35,15 \\
\hline SC & 4,38 & 20,36 \\
\hline RS & 9,57 & 44,49 \\
\hline REGIÃO SUL & 21,50 & 100,00 \\
\hline
\end{tabular}

FONTE: Elaboração das autoras com base no Censo Agropecuário 2006 (IBGE).

TABELA 8 - PARTICIPAÇÃO RELATIVA DE ESTABELECIMENTOS AGROPECUÁRIOS COM ELETRODOMÉSTICOS EM RELAÇÃO AO TOTAL DE ESTABELECIMENTOS (\%)

\begin{tabular}{l|r}
\hline BRASIL & 78,10 \\
\hline REGIÃO SUL & 86,38 \\
\hline PR & 82,34 \\
\hline SC & 91,36 \\
\hline RS & 87,59 \\
\hline
\end{tabular}

FONTE: Elaboração das autoras com base no Censo Agropecuário 2006 (IBGE).

Constata-se que o mais popular dentre esses eletrodomésticos é o rádio, estando esse presente em 89,64\% dos estabelecimentos que possuem algum tipo de eletrodoméstico no Brasil, seguido pela televisão, com um percentual de 26,75\% antena comum e 58,85\% antena parabólica. Apenas 4,54\% destes possuem computador e 1,87\% possuem acesso à internet. $\mathrm{Na}$ região sul, esses valores são: rádio (96,53\%); televisão com antena comum $(29,64 \%)$; televisão com antena parabólica (67,43\%); computador (9,59\%); e acesso à internet $(3,43 \%)$. Dos estabelecimentos do Brasil que possuem computador, 45,39\% estão situados na região sul e dos que possuem acesso à internet, 39,52\% encontram-se na mesma.

\section{ASPECTOS AMBIENTAIS}

O número de estabelecimentos agropecuários do Brasil que utilizam adubo é equivalente a $35,52 \%$ do total de estabelecimentos. Dentre os estados da região sul, dos estabelecimentos situados no Rio Grande do Sul, 78,54\% do total usam adubo, seguido de Santa Catarina com 74,99\% e do Paraná com 63,84\%. No Brasil, 1,83 milhão de estabelecimentos utilizam adubo, sendo a parcela referente aos estabelecimentos da região sul 39,64\% desse valor.

Em relação ao uso de agrotóxicos no Brasil, 26,97\% do total de estabelecimentos utilizam algum tipo de agrotóxico. Dentre os estados da região sul, Santa Catarina é o que possui maior número de estabelecimentos que os utilizam, representando eles 64,16\% do total de estabelecimentos do estado, ficando o Rio Grande do Sul em segundo, com 62,03\% e o Paraná 
com 54,64\%. O valor referente ao número total de estabelecimentos agropecuários que utilizam agrotóxicos no Brasil é 1,39 milhão, obtendo a região sul uma parcela desses equivalente a $43,04 \%$.

No que se refere ao número de estabelecimentos agropecuários do Brasil que utilizam agricultura orgânica, esse é equivalente a apenas 1,75\% do total de estabelecimentos. Dentre os estados da região sul, o Paraná é o que possui maior número de estabelecimentos que a utiliza, representando eles 2,03\% do total de estabelecimentos do estado, seguido do Rio Grande do Sul, com 1,93\% e de Santa Catarina, com 1,66\%. O valor referente ao número total de estabelecimentos agropecuários que utilizam agricultura orgânica no Brasil é 90,49 mil, obtendo a região sul uma parcela de estabelecimentos que utilizam agricultura orgânica equivalente a $21,30 \%$ em relação ao país.

No que tange às práticas agrícolas, o número de estabelecimentos agropecuários do Brasil que utilizam algum método (plantio em nível; queimadas; rotação de culturas; pousio ou descanso dos solos; proteção e/ou conservação de encostas; uso de lavouras para reforma e/ou renovação de pastagens; e/ou uso de terraços) é equivalente a 57,94\% do total. Dentre os estados da região sul, o Rio Grande do Sul é o que possui maior número de estabelecimentos que as utilizam, representando $73,34 \%$ do total do estado, seguido do Paraná $(71,41 \%)$ e de Santa Catarina $(70,12 \%)$.

A região sul obtém 27,29\% do número de estabelecimentos do país que utilizam plantio em nível e expressivos 52,63\% que realizam rotação de culturas. Quanto às queimadas, enquanto $13,56 \%$ dos estabelecimentos agropecuários do país as realizam, esse percentual é de apenas $1,47 \%$ na região sul, estando somente $2,11 \%$ dos estabelecimentos que as realizam situados na região.

\section{CONSIDERAÇÕES FINAIS}

Através da análise das dimensões econômica, social e ambiental dos estabelecimentos agropecuários da região sul do Brasil é possível perceber a importância e o nível de desenvolvimento dessa no contexto nacional agropecuário. Ao desagregar a análise por dimensão e por estado, percebe-se que o Rio Grande do Sul destaca-se no que se refere a dimensão econômica e Santa Catarina na dimensão social. Na dimensão ambiental não existe uma vantagem clara de um estado sobre os demais. O Paraná destaca-se no que se refere ao número de estabelecimentos que praticam a agricultura orgânica.

Percebe-se, analisando os dados agregados, que a região sul é mais homogênea do que se comparada com o restante do Brasil. Isso não significa dizer que não existam disparidades 
internas. O estudo das desigualdades internas será analisado em trabalho posterior, a partir da construção de um indicador socioeconômico e ambiental agropecuário para os municípios da região sul do país.

\section{REFERÊNCIAS}

IBGE. Censo Agropecuário 2006. Disponível em: <http://www.sidra.ibge.gov.br/bda/pesquisas $/ \mathrm{ca} /$ default.asp?o $=2 \& \mathrm{i}=\mathrm{P}>$. 
